\title{
Technical Efficiency of Management wise Schools in Secondary School Examinations of Andhra Pradesh by CCR Model
}

\author{
Raju Nellutla ${ }^{1}$, V.V Haragopal ${ }^{2}$, D. Vijaya laxmi ${ }^{3}$ \\ ${ }^{I}$ (Associate Professor, Department of Statistics, Guru Nanak Institutions Technical Campus, Hyderabad, \\ Telangana, India) \\ ${ }_{2}^{2}$ (Professor, Department of Statistics, Osmania University, Hyderabad, Telangana, India) \\ ${ }^{3}$ (Associate Professor, Department of Statistics, Kakatiya University, Warangal, Telangana, India)
}

\begin{abstract}
In this paper we measuring the Board of Secondary education data by CCR Model for the Andhra Pradesh state for the academic years 2012-2013 and 2013-2014 to see the Pattern through CCR Technical Efficiency of the Management wise school results in prior to the division of state in to two separate states. The Performance of the Management wise schools are presented along with the Peer Management Schools performance of the state as a whole.
\end{abstract}

Keywords: DEA, Linear Programming Problem, Primal Problem, Performance, Technical Efficiency.

\section{Introduction}

For decades, Many applied fields share common concern over design and action on how to improve the data analytics. The concepts of best practices is to deliberate action in Private and Government sectors for improvement. There are three important characteristics associated with a " best practice" : a comparative process, an action and link between an action and some out comes or goals. From 1980's on wards, researchers started to direct their efforts towards extending " best practice" to Education. This led to school improvement initiatives and studies on the characteristics of School Environment conductive to learning [1]. In various parts of the world Researchers like Rhodes, Cooper and Thanassoulis started seeking appropriate measurement methodologies for school efficiency. Studied about the efficiency in U.S.A. Private Universities in comparison to the Public Universities, by applying Data Envelopment Analysis Model and they regarded as Decision Making Units on the university as whole and analysed the data [2] and also applied DEA model to assess the performance of Decision Making Units viz., Engineering, Mathematics and Physics departments of a set of universities in U.K.[3]. These outcomes are obtained from different specifications of inputs and outputs. Performance of Management Schools in Secondary School Examinations of Andhra Pradesh State for academic years 2009-10 and 2010-11by Data Envelopment Analysis are assessed [4]. The educational process is characterized by multiple outcomes such as the achievement of academic results and found many interesting patterns.

\section{Data Envelopment Analysis}

Data Envelopment Analysis is relatively "data oriented" approach for evaluating the performance of a set of peer entities called decision making entities, Which convert multiple inputs in to multiple outputs .In the recent years, the DEA has emerged in to a greater variety of application for using evaluating the performance of many different kinds of entities engaged in many different activities in many different contexts in many different countries world over. Critical Data Envelopment Analysis of Hospital efficiency in India and found interesting results in health care issues [5].

In the present study we attempt to deal with the issue of measuring the efficiency of the participating Management schools in Andhra Pradesh to summarize the measure of efficiency of the data. These evaluations can be conducted not only at the organization level but also in sub units such as number of boys, number of girls and total number of students appeared in examination and their results. This paper shows how Data Envelopment Analysis (DEA) can be used to guide secondary schools to improved performance through rolemodel identification and target setting in a way that recognizes the multi-outcome nature of the education process and reflects the relative desirability of improving individual outcomes. The approach presented in the paper draws from a DEA-based assessment of the schools management wise. In this study we analyse the case data on Board of Secondary Education (SSC) of Andhra Pradesh to assess which Management School fares well academic years 2012-13 and 2013-14 by Data Envelopment Analysis.

2.1 Educational Inputs: The resources or input indicators are units of measurement, which represent the factors used to carry out the delivery of services. The identification and measurement of these factors is crucial in a fair evaluation of the economy and efficiency in the programs and services management. Previous studies on other 
Technical Efficiency of Management wise Schools in Secondary School Examinations of Andhra ..

performance models [6] have shown that inputs of universities can be categorized in various ways. Here Educational Inputs are Management wise number of boys, number of girls and total number of students appeared in the Examination.

2.2 Educational Outputs: Output indicators measure the level of activity of programs and services. Furthermore, it is always useful to disclose indicators that provide information about the quantity and the quality of the activity [7]. The quality, as an attribute that affects the user's perception, can also modify the productive process input/output relation. For this reason, it must be considered to access the efficiency of the process. Constructed DEA methodology to measure risk of commercial Banks[8] and also constructed Data Envelopment Analysis to know the Performance of the districts in SSC Public Examinations for the years 2009 - 2011 of Andhra Pradesh [9]. In our case by considering the outputs are Management wise number of Boys , number of Girls and Total number of students passed in Public Examination.

\section{Efficiency}

The efficiency analysis is always computed to assess the performance of an organization. The Efficiency is an important factor in economic analysis, where the process has a single input and single output, then Efficiency is defined as :

$$
\text { Efficency }=\frac{\text { Output }}{\text { Input }}
$$

The theory of production from the economic point of view then can be considered as a formal model to link inputs and outputs, This theory has several strengths. First, some formal relationship between inputs and outputs exists and a " best practice " can be identified by comparing different units transforming in to inputs to output where all units are assessed relative to that of optimum.

The production process that occurs in schools seems to have the same characteristics of the above economic model in the business sector- utilization of physical and human resources as inputs to compute outputs as shown in below.

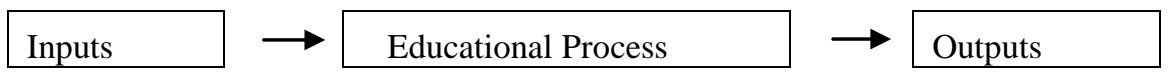

Figure 1. Educational Transformation Input/ Output Process

3.1 The CCR Model: In Data Envelopment Analysis( DEA) the most widely used model is CCR Model . A Constant Return to Scale relationship is assumed between Inputs and Outputs. It was the First Data Envelopment Analysis model to be developed CCR after Charnes, Cooper and Rhodes who introduced this model [10-11].This model calculates the Overall Efficiency (OE) for each unit, Where we get both Technical Efficiency and Scale Efficiency are aggregated in to one value.

The Primal CCR model is explained as follows

Decision Making Units $D_{M U}$ : The $\mathrm{j}^{\text {th }}$ Decision Making Unit $\mathrm{j}=1,2,3, \ldots, \mathrm{n}$.

$x_{\mathrm{ij}}$ : The amount of the $\mathrm{i}^{\text {th }}$ input of the $\mathrm{j}^{\text {th }}$ DMU $\mathrm{x}_{1 \mathrm{j}}, \mathrm{x}_{2 \mathrm{j}}, \mathrm{x}_{3 \mathrm{j}}, \ldots, \mathrm{x}_{\mathrm{nj}}$

$y_{i j}$ : The amount of the $\mathrm{j}^{\text {th }}$ output of the $\mathrm{j}^{\text {th }} \mathrm{DMU} \mathrm{y}_{1 \mathrm{j}}, \mathrm{y}_{2 \mathrm{j}}, \mathrm{y}_{3}, \ldots, \mathrm{y}_{\mathrm{sj}}$.

$v_{i}$ : The weight assigned to the $i^{\text {th }}$ input $i=1,23, \ldots, n$.

$\mathrm{u}_{\mathrm{r}}$ : The weight assigned to the $\mathrm{r}^{\text {th }}$ output $\mathrm{r}=1,23, \ldots, \mathrm{s}$.

The Fractional Programming Problem ( FPP) is

Maximize $\mathrm{R}=\frac{u_{1} y_{1 k}+u_{2} y_{2 k}+\cdots+u_{s} y_{s k}}{v_{1} x_{1 k}+v_{2} x_{2 k}+\cdots+v_{m} x_{m k}}$

Subject to Constraints: $\frac{u_{1} y_{1 j}+u_{2} y_{2 j}+\cdots+u_{s} y_{s j}}{v_{1} x_{1 j}+v_{2} x_{2 j}+\cdots+v_{m} x_{m j}} \leq 1 \quad \mathbf{j}=1,2, \ldots, \mathbf{n}$

and Non negativity $u_{1}, u_{2}, u_{3}, \ldots, u_{s} \geq 0 \quad v_{1}, v_{2}, v_{3}, \ldots, v_{m} \geq 0$

The ratio of input and output should not exceed 1 for every decision making unit. The objective is to Maximize the Decision Making Units. The optimal value of $\mathrm{R}^{*}$ is at most one. Mathematically, non negativity constraints (4) is not sufficient for the fractional terms in (3) to have a positive value. Now we replace the Factional Program (FP) by the following Linear Programming Problem (LPP),

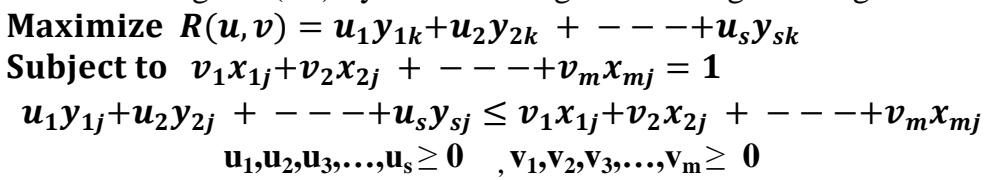

Optimal Solution $\left(\mathbf{v}^{*}, \mathbf{u}^{*}, \mathbf{R}^{*}\right)$

The reference set 
$R_{s}=\left\{j: \sum_{r=1}^{s} u_{r}^{*} y_{r j}=\sum_{i=1}^{m} v_{i}^{*} x_{i j} \quad j=1,2,3, \ldots, n\right\}$

The Reference set $R_{s}$ is the Primal Problem. The Primal Problem becomes

$$
\begin{aligned}
& \text { Maximize } R^{*}\left(v^{*}, \mathbf{u}^{*}\right)=\sum_{r=1}^{s} u_{r} y_{r k} \\
& \text { Subject to constraints: } \sum_{r=1}^{s} u_{r}^{*} y_{r j}-\sum_{i=1}^{m} v_{i}^{*} x_{i j} \leq 0 \quad j=1,2,3, \ldots, n
\end{aligned}
$$

$\sum_{i=1}^{m} v_{i} x_{i k}=1$

$$
\text { Non negativity } \quad v_{i} \geq 0 \quad u_{r} \geq 0
$$

The above linear Programming Problems yield the Optimal Solution $\mathrm{R}^{*}$, where efficiency score is called Technical Efficiency T.E or CCR Efficiency for the particular DMU $\mathrm{J}_{\mathrm{j}}$ and Efficiency scores for all of them are obtained by repeating them for each $D M U_{j}, j=1,2, \ldots . n$. The value of $R^{*}$ is always less than or equal to unity. DMUs for which $\mathrm{R}^{*}<1$ are relatively inefficient and those for which $\mathrm{R}^{*}=1$ are relatively efficient, having their virtual input-output combination points on the frontier. The frontier itself consists of linear facts spanned by efficient units of the data, and the resulting frontier production function has no unknown parameters.

3.2 The Output-oriented Data Envelopment Model: Now we consider two models. Those models are inputoriented model and output-oriented model. In input-oriented model all DMUs deemed to produce with given amount of outputs with the smallest possible amount of inputs. In output-oriented model all DMUs deemed to produce with given amount of inputs with the highest possible amount of outputs. Whose objective is to minimize inputs while producing at least given output level. This type of model is called input- oriented CCR Model. A model whose objective is to maximize outputs while using no more than the observed amount of any input. This is referred to as the Output oriented CCR model.

Output-Oriented and Input-Oriented CCR Model is as follows

$$
\begin{array}{lc}
\left(\mathrm{DLPO}_{\mathrm{CCR}}\right) & \operatorname{Max}(\mu, \eta)=\eta \\
\text { subject to constraints: } & x_{o}-X \mu \geq 0 \\
& \eta y_{o}-Y \mu \leq 0 \\
\mu & \geq 0
\end{array}
$$

An optimal solution of output oriented model can be derived directly from an optimal solution of the inputoriented model given as fallows . Let us define

$$
\lambda=\frac{\mu}{\eta}, \quad R=\frac{1}{\eta}
$$

ThenDLPO ${ }_{\mathrm{CCR}}$ becomes

$\left(\mathrm{DLPO}_{\mathrm{CCR}}\right)$

$$
\begin{aligned}
\operatorname{Min}(\mathrm{R}, \lambda) & =\mathrm{R} \\
R x_{o}-X \lambda & \geq \\
y_{o}-Y \lambda & \leq 0 \\
\lambda & \geq 0
\end{aligned}
$$

Which is the input-oriented CCR Model. Thus, an optimal solution of the output-oriented CCR Models to that of the input-oriented model via:

$$
\eta^{*}=\frac{1}{R^{*}}, \mu^{*}=\frac{\lambda^{*}}{R^{*}}
$$

The slack $\left(\mathrm{t}^{-}, \mathrm{t}^{+}\right)$of the output -oriented model is defined by:

$$
\begin{aligned}
& \mathrm{X} \mu+t^{-}=x_{o} \\
& \mathrm{Y} \mu-t^{+}=\eta y_{o}
\end{aligned}
$$

These values are also related to the input-oriented model

Here $R^{*} \leq 1$, so returning to $\eta^{*}$ satisfies

$$
t^{-*}=\frac{s^{-*}}{R^{*}}, t^{+*}=\frac{s^{+*}}{R^{*}}
$$

$\eta^{*} \geq 1$

The higher value of $\eta^{*}$, the less efficient DMU. $R^{*}$ express the input reduction rate, when $\eta^{*}$ describes the output enlargement rate. From the above relation, we can conclude that an input- oriented CCR model will be efficient for any DMU if and only if it is also efficient when the output-oriented CCR model is used to evaluate its performance. As per the above model we implement empirical model evaluation for the 
data considered in the next section by explaining the Potential Improvement (P.I) and Reference Comparison (R.C) . We first explained about Potential Improvement (P.I) and Reference Comparison (R.C) .

3.3 Potential Improvement: An efficient study not only provides an efficiency score per each unit but also indicates by how much and in what areas an inefficient unit need to improve in order to efficiency. This information can enable targets to be set which could help inefficient units to improve their Performance.

3.4 Reference comparison: If the assessment of units was found as inefficient then it is felt to be justified then the information provided can be used as a basis for setting targets for the units.As a first step in setting targets, the inefficient unit should be compared with the units in its reference set.

3.5 Peer Group: Data Envelopment Analysis identifies for each inefficient unit a set of excellent units, called Peer Group, which includes those units that are efficient if evaluated with the optimal weights of inefficient unit. The Peer Group, made up of Decision Making Units which are characterized by Operating methods similar to the inefficient unit being examined, which is a realistic term of comparison which unit aim to imitate in order to improve its performance.

3.6 Constant Returns to Scale: The efficiency measures are based on Constant Returns to Scale technology (CRS). This implies that the production technology under consideration is such, that an increase in all the inputs by some proportion results in an increase in all the outputs by the same proportion. The variable returns to scale result in a non- proportionate change (increase or decrease) in the outputs. The Returns to scale and the difference between the input-reducing and the output-increasing measures are illustrated on figure by considering the Decision Making Units (DMUS) D1, D2,D3,D4.

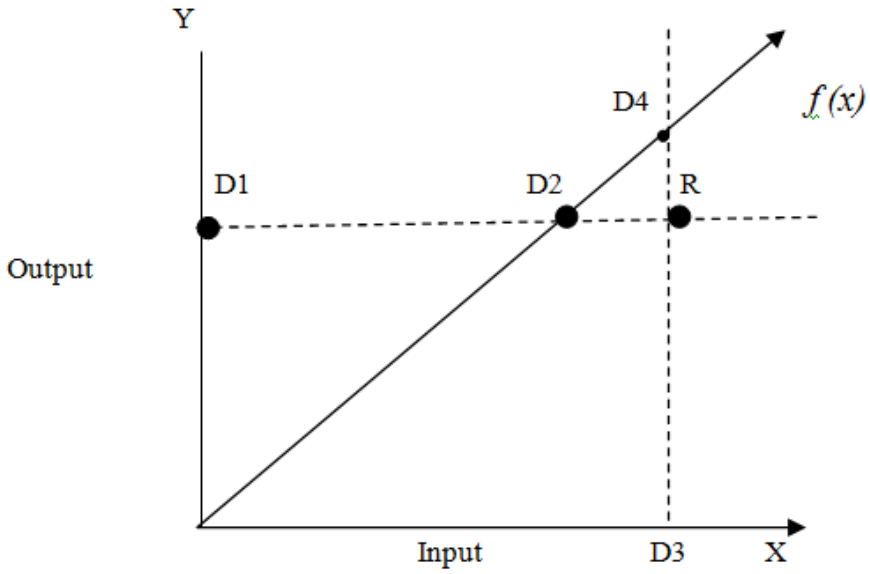

Figure 2. Constant Returns to Scale (CRS)

From the above figure we understand that, a production of a single output is illustrated graphically. In fig (2) it can be seen that the function $f(x)$, where $f(x)$ is a straight line and has a single slope. Hence, for every unit increase in the input that goes into the process, the output produced increases by a constant proportional quantity, hence it represents Constant Returns to Scale (CRS).

In this case, $\mathrm{R}$ could be projected onto the frontier either under an input- reducing consideration or an output increasing consideration. D2 and D4 are projected points on the frontier obtained for comparison.

\section{Empirical Study}

It is well known that every state in India holds a Public Examination at $10^{\text {th }}$ grade. This data was chosen to see the Performance of the Management wise Schools in 23 districts of Andhra Pradesh. The Secondary School Certificate (S.S.C) Public Examinations data for the academic years 2012-2013 and 2013-2014 of Andhra Pradesh for the 23 districts were considered as the data for measuring the efficiency of the Management schools in this state.

In SSC Public Examinations, March,2013, 1049902 Regular Candidates have appeared for the SSC Public Examinations. Out of 1049902 candidates, 539335 number of boys and 510567 number of girls Candidates have appeared for SSC Examinations.

In SSC Public Examinations, March,2014, 1061703 Regular Candidates have appeared for the SSC Public Examinations. Out of 1061703 candidates, 544538 number of boys and 517165 number of girls Candidates have appeared for SSC Examinations.

There is an increase of 11801 regular candidates in 2013-14 examination while comparing 2012-2013. Here we consider the data of different managements from which the Candidates appeared for the Examination and to see the efficiency of these management schools performance in the state. 
Technical Efficiency of Management wise Schools in Secondary School Examinations of Andhra ..

The Results of Data Envelopment Analysis (DEA) for the academic year 2012-13 are presented below:

Table 1 Technical Efficiency of Management wise Schools for the academic year 2012-2013

\begin{tabular}{|l|l|l|l|l|l|l|}
\hline $\begin{array}{l}\text { S. } \\
\text { No }\end{array}$ & $\begin{array}{l}\text { Name of the } \\
\text { Management }\end{array}$ & Score & $\begin{array}{l}\text { Technical } \\
\text { Efficiency } \\
(\text { CCR })\end{array}$ & $\begin{array}{l}\text { No. of } \\
\text { References }\end{array}$ & $\begin{array}{l}\text { No. of } \\
\text { Peers }\end{array}$ & Name of the Peers \\
\hline 1 & A.P.R.E.I.S & 100 & 1.0000 & 2 & 0 & A.P.R.E.I.S \\
\hline 2 & A.P.S.W.R.E.I.S & 100 & 1.0000 & 5 & 0 & A.P.S.W.R.E.I.S \\
\hline 3 & A.P.T.W.R.E.I.S & 98.66 & 0.9866 & 0 & 2 & A.P.R.E.I.S, Private \\
\hline 4 & Aided School & 91.43 & 0.9143 & 0 & 2 & A.P.S.W.R.E.I.S, Private \\
\hline 5 & Government Schools & 87.08 & 0.8708 & 0 & 2 & A.P.S.W.R.E.I.S, Private \\
\hline 6 & Municipal Schools & 85.35 & 0.8535 & 0 & 2 & A.P.S.W.R.E.I.S, Private \\
\hline 7 & Private Schools & 100 & 1.0000 & 6 & 0 & Private \\
\hline 8 & $\begin{array}{l}\text { Zilla Parishad } \\
\text { Schools }\end{array}$ & 91.53 & 0.9153 & 0 & 2 & A.P.S.W.R.E.I.S, Private \\
\hline
\end{tabular}

* A.P.R.E.I.S: Andhra Pradesh Residential Educational Institutions Society

* A.P.S.W.R.E.I.S: Andhra Pradesh Social Welfare Residential Educational Institutions Society

* A.P.T.W.R.E.I.S: Andhra Pradesh Tribal Welfare Residential Educational Institutions Society

From the above Table 1 the Technical Efficiency(T.E) variation is for the 8 Management Schools has the following bound $0.8535 \leq \mathrm{R}^{*} \leq 1.000$. Also Three Management Schools has been emerged as efficient namely A.P.R.E.I.S (Andhra Pradesh Residential Educational Institutions Society) , A.P.S.W.R.E.I.S (Andhra Pradesh Social Welfare Residential Educational Institutions Society) and Private. The remaining management schools input loses due to Technical efficiency.

From the Table 1 it is clear that A.P.R.E.S.I , A.P.S.W.R.E.S, and Private are Technically(CCR) Efficient when compared to the rest of the 8 Management Schools. It is noticed that the Peers to the all other Management Schools seems to be A.P.R.E.S.I, A.P.S.W.R.E.I.S and Private. The Technical Efficiency of A.P.T.W.R.E.I.S (Andhra Pradesh Tribal Welfare Residential Educational Institutions Society) is 0.9866. Hence A.P.T.W.R.E.I.S is technically inefficient. If returns to scale are constant it could have to produced its current outputs 0.9866 ratio of inputs. Thus removal of all inefficiencies is achieved by reducing all inputs by 0.0134 or Approximately, $1.34 \%$ of their observed values. In fact, based on the reference set and peer weight $\lambda^{*}$ , we can express the input and output values needed to bring A.P.T.W.R.E.I.S in to efficient status. This information helps A.P.T.W.R.E.I.S managements to make an appropriate decisions as to how to improve schools efficiency. Similarly we can bring remaining inefficient colleges in to efficient status by using CCR model. A.P.R.E.S.I, A.P.S.W.R.E.I.S and Private Managements role models in this State. Since these colleges CCR Technical Efficiency is 1.000. Private management is having highest references. Peer contribution of this management is more comparable to other Management schools.

1. In Data Envelopment Analysis every inefficient Decision making units (Managements) have 1 or more role models respectively.

For example A.P.S.W.R.E.I.S, Private Management Schools are the role models for Aided Management schools.

2. Efficient DMUs (Managements), they themselves will be the role models.

For example A.P.R.E.I.S has efficient, its technical efficiency is 1.000 and itself is a role model.

The Distribution of Scores Graph for the academic Year 2012-2013 is presented below:

Distribution of scores

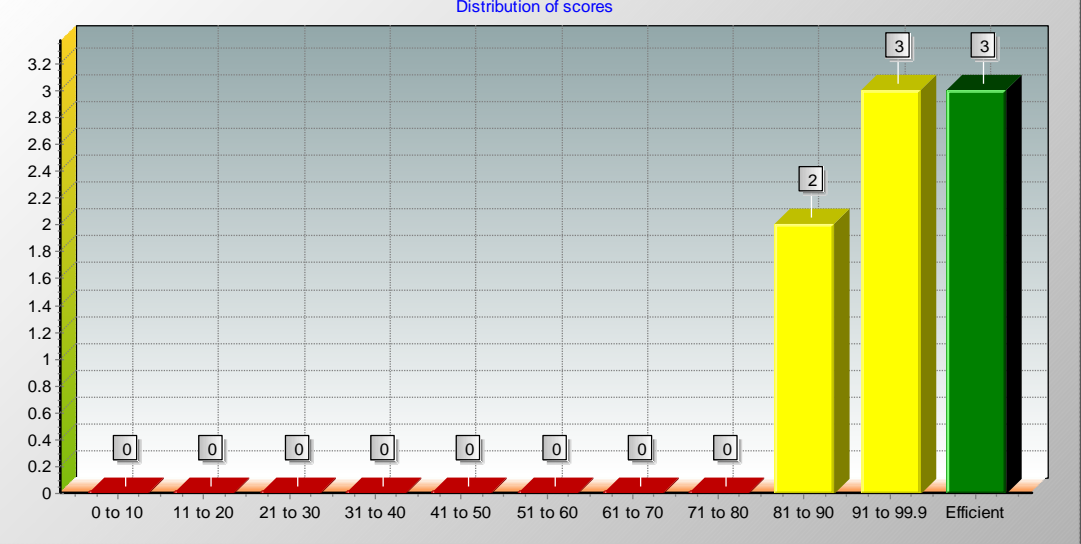

Figure 2 . The Distribution of Scores Graph for the academic Year 2012-2013 
Management wise reference graph for the academic year 2012-13 is presented below:

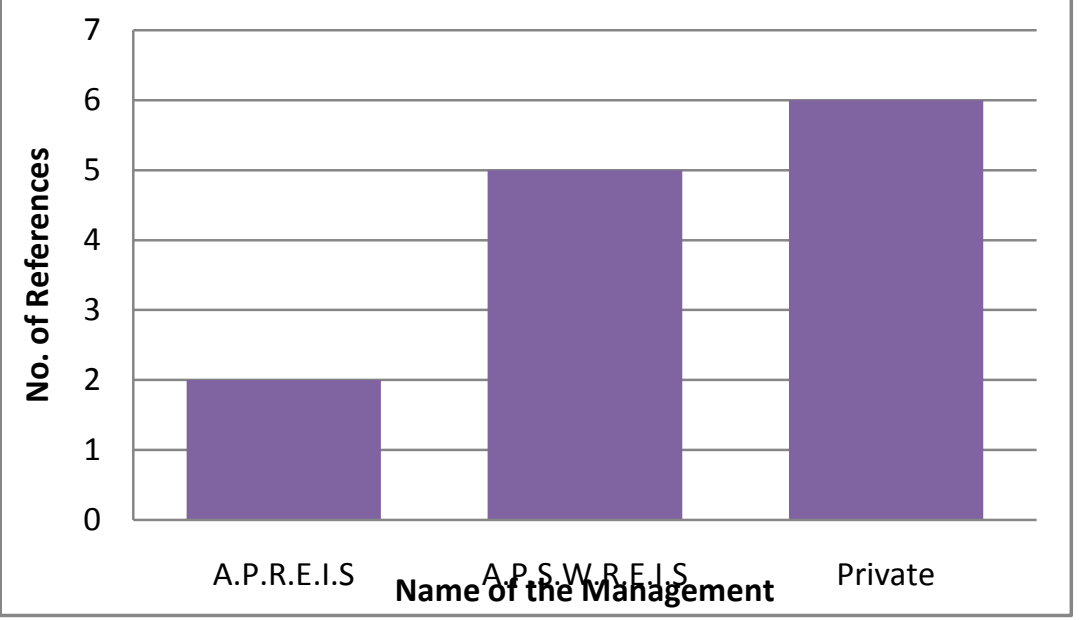

Figure 3. Management wise reference graph for the academic year 2012-13

The CCR Technical Efficiency of management wise schools for the academic year is presented below.

Table 2 Technical Efficiency of Management wise Schools for the academic year 2013-2014

\begin{tabular}{|l|l|l|l|l|l|l|}
\hline S. No & $\begin{array}{l}\text { Name of the } \\
\text { Management }\end{array}$ & Score & $\begin{array}{l}\text { Technical } \\
\text { Efficiency } \\
\text { (CCR) }\end{array}$ & $\begin{array}{l}\text { No. of } \\
\text { References }\end{array}$ & $\begin{array}{l}\text { No. of } \\
\text { Peers }\end{array}$ & Name of the Peers \\
\hline 1 & A.P.R.E.I.S & $100 \%$ & 1.000 & 2 & 0 & A.P.R.E.I.S \\
\hline 2 & A.P.S.W.R.E.I.S & $100 \%$ & 1.000 & 6 & 0 & A.P.S.W.R.E.I.S \\
\hline 3 & A.P.T.W.R.E.I.S & $96.4 \%$ & 0.964 & 0 & 3 & $\begin{array}{l}\text { A.P.R.E.I.S } \\
\text { A.P.S.W.R.E.I.S, Private }\end{array}$ \\
\hline 4 & Aided Schools & $92.58 \%$ & 0.9258 & 0 & 2 & A.P.S.W.R.E.I.S, Private \\
\hline 5 & Government Schools & $88.74 \%$ & 0.8874 & 0 & 2 & A.P.S.W.R.E.I.S, Private \\
\hline 6 & Municipal Schools & $88.5 \%$ & 0.885 & 0 & 2 & A.P.S.W.R.E.I.S, Private \\
\hline 7 & Private Schools & $100 \%$ & 1.000 & 6 & 0 & Private \\
\hline 8 & $\begin{array}{l}\text { Zilla Parishad } \\
\text { Schools }\end{array}$ & $93.68 \%$ & 0.9368 & 0 & 2 & A.P.S.W.R.E.I.S, Private \\
\hline
\end{tabular}

From the above Table 2 the Technical Efficiency variation is for the 8 Management Schools has the following bound $0.885 \leq \mathrm{R}^{*} \leq 1.000$. Out of 8 Management Schools only three has emerged as efficient namely A.P.R.E.I.S (Andhra Pradesh Residential Educational Institutions Society) , A.P.S.W.R.E.I.S (Andhra Pradesh Social Welfare Residential Educational Institutions Society) and Private the remaining Management Schools input loses due to Technical efficiency. The Technical Efficiency of Municipal Management schools is 0.885 . Hence Municipal Management is technically partially inefficient. If returns to scale are constant it could have to produced its current outputs 0.885 ratio of inputs. Thus removal of all inefficiencies is achieved by reducing all inputs by 0.105 or Approximately, $10.5 \%$ of their observed values .In fact, based on the reference set and Peer weight $\lambda^{*}$, we can express the input and output values needed to bring Municipal Management schools in to efficient status. Similarly we can bring remaining inefficient Managements in to efficient status by using CCR model.

It is Evident that from the Table 2 that three Management Schools fared well as per the CCR Technical Efficiency. When we compare 2012-2013 and 2013-2014 data, we notice that there is no significant changes with respect to the A.P.R.E.S.I, A.P.S.W.R.E.I.S and Private is faring well in both the academic Years. Even the bound differs with respect to the data for both years. We also tabulate in Table 3 the comparison of these two years how the Managements Performed.

A.P.S.W.R.E.I.S and Private Management is having highest references. Peer contribution of these managements is more compare to other Management schools. A.P.S.W.R.E.I.S, Private Management Schools are the role models for Zilla Parishad Management schools. Andhra Pradesh Residential Educational Institutions Society (A.P.R.E.I.S) has efficient, its technical efficiency is 1.000 and by itself is a role model. 
Technical Efficiency of Management wise Schools in Secondary School Examinations of Andhra ..

The Distribution of Scores Graph for the academic Year 2013-2014 is presented below:

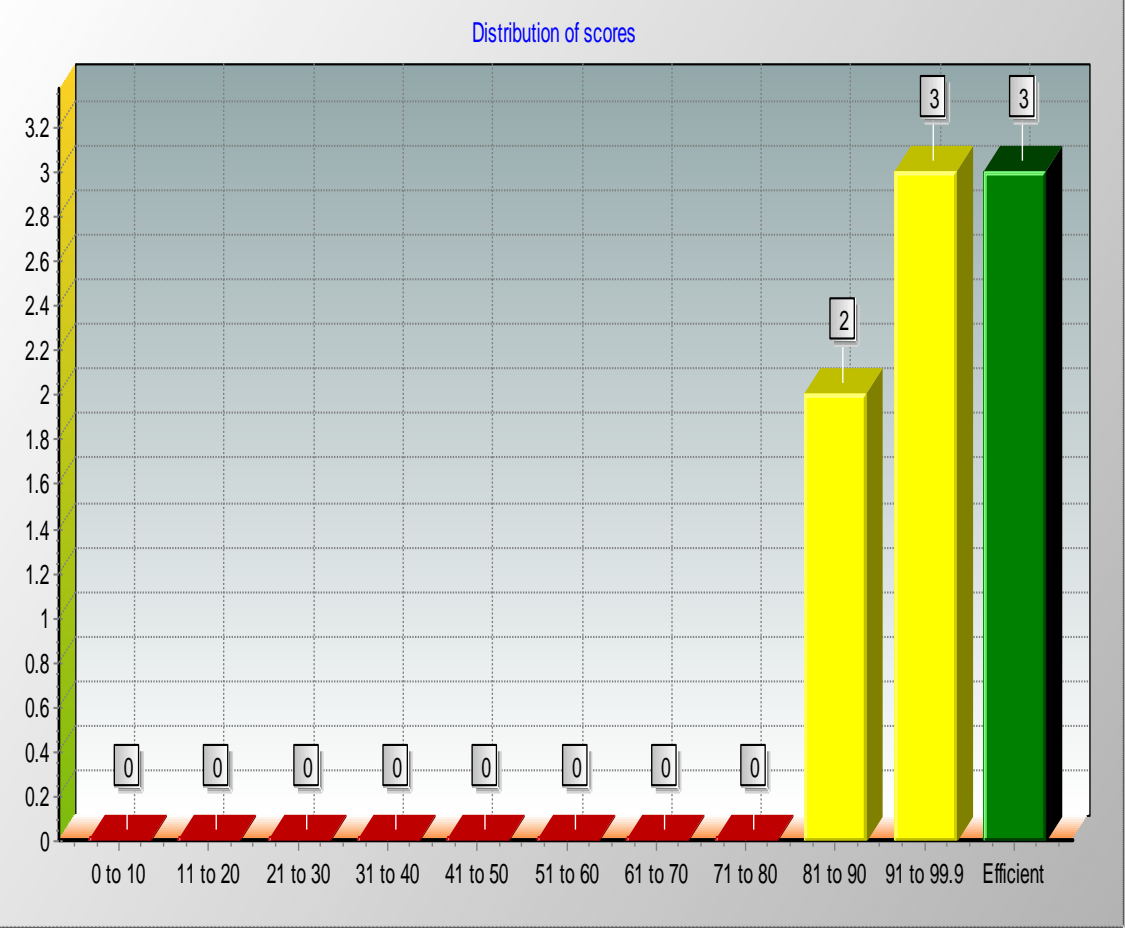

Figure 4. The Distribution of Scores Graph for the academic Year 2013-2014

Management wise reference graph for the academic year 2013-14 is presented below

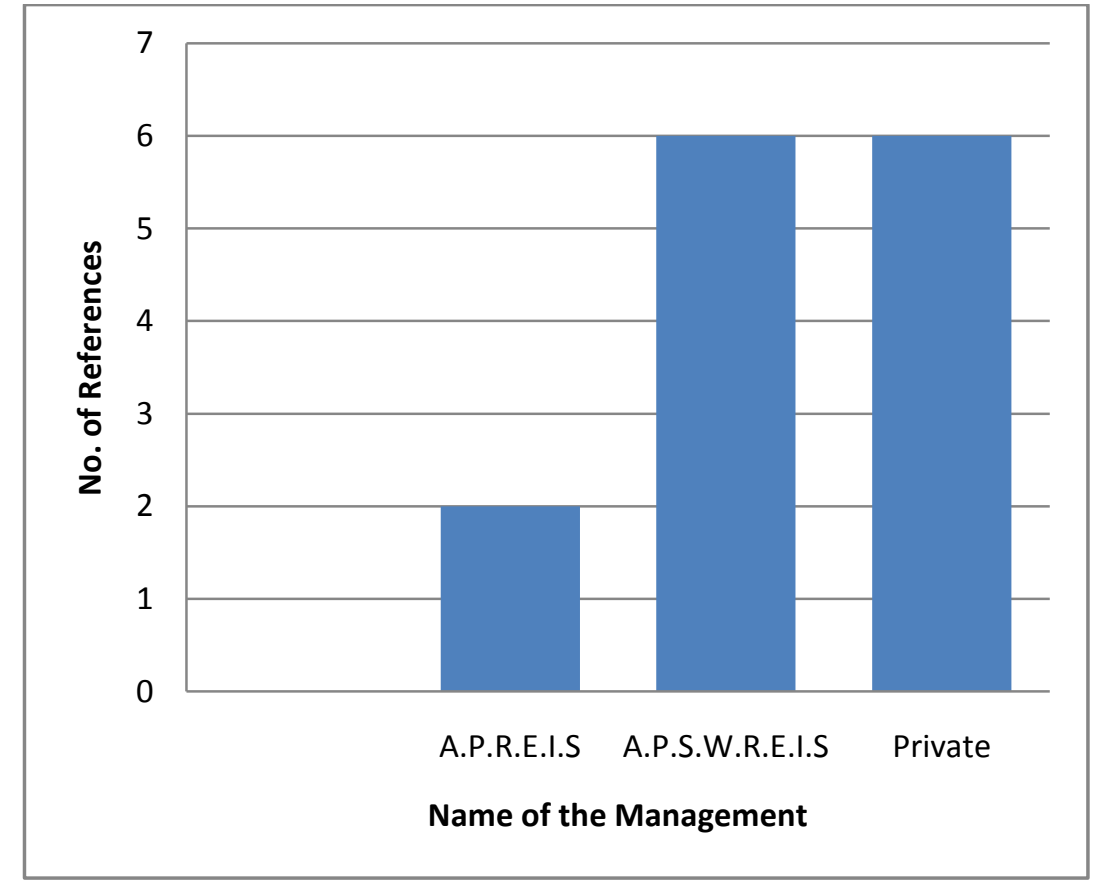

Figure 3. Management wise reference graph for the academic year 2013-14

The Technical efficiency of the Management wise schools for the academic years 2012-13 and 2013-14 comparison is presented below: 
Technical Efficiency of Management wise Schools in Secondary School Examinations of Andhra ..

Table 3 The CCR Scores Distribution Comparison

\begin{tabular}{|l|l|l|}
\hline \multicolumn{1}{|c|}{ Score } & 2012-2013 & 2013-2014 \\
\hline $100 \%$ Efficiency & A.P.R.E.I.S ,A.P.S.W.R.E.I.S, Private & A.P.R.E.I.S , A.P.S.W.R.E.I.S, Private \\
\hline Scores 91-99.9 & $\begin{array}{l}\text { A.P.T.W.R.E.I.S, Aided Schools, } \\
\text { Zilla Parishad Schools }\end{array}$ & $\begin{array}{l}\text { A.P.T.W.R.E.I.S, Aided Schools, Zilla } \\
\text { Parishad Schools }\end{array}$ \\
\hline Scores 81-90 & $\begin{array}{l}\text { Government Schools, Municipal } \\
\text { Schools }\end{array}$ & Government Schools, Municipal Schools \\
\hline Scores below 80 & No Schools & No Schools \\
\hline
\end{tabular}

\section{Conclusion}

From this Analysis we observe that in both the academic years three Management Schools commonly performed efficiently i.e A.P.RE.S.I, A.P.S.W.R.E.I.S, Private for the two consecutive academic years performed well in 2012-2013. Remaining Management Schools are not maintained their performances. For the academic year 2013-14 three Management Schools namely A.P.R.E.S.I, A.P.S.W.R.E.I.S and Private Management schools Performed efficiently as per CCR Model . With this pattern we can say that three Management Schools shown above are performing well while there should be Potential Improvement is required for Aided, A.P.T.W.R.E.I.S ,Government, Municipal , Zilla Parishad Management Schools which are inefficient units to improve in their Performance as compared to the efficient schools analysed. The reason for this could be strength and other infrastructural facilitates in the schools.

\section{Journal Papers}

\section{References}

[1]. Rutter, M. \& Maughan, B. (2002) “ School effectiveness findings 1970-2002 " Journal of School Psychology ,vol.40, No.6, pp.451-475.

[2]. Rhodes, E.Y. and Southwick, L. (1986) "Determinants of Efficiency in Public and Private Universities", Department of Economics, University of South Carolin.[2]

[3]. Kwimbere, F.J. (1987) " Measuring efficiency in not-for-profit organizations: an attempt to evaluate efficiency in selected UK university departments". School of Management, University of Bath.

[4]. Raju Nellutla, V. V. Haragopal,(2015) "Data Envelopment Analysis of SSC Public Examinations 2009 -2011 of Andhra Pradesh" Global Journal for Research Analysis, vol -4,issue 7,pp.141-144.

[5]. M. Goverdhan, Raju Nellutla, V. V Haragopal (2016) "A Critical Data Envelopment Analysis of Hospital efficiency in India ", International Journal of Scientific Research, Vol-5,issue2,pp.471-475.

[6]. Johnes, J., (1996) "Performance assessment in higher Education in Britain" European Journal of Operational Research vol. 2, pp. 18-33.

[7]. Pina ,V., Y Torres, L., (1995) "Analyse through DEA Teaching activity of the Account Department" in Spanish Public University.

[8]. Subramanyam, T., and C.S Reddy (2008) "Measuring the Risk Efficient in Indian Commercial Banking -DEA approach" East West Journal of Economics and Business, Vol XI $(1 \& 2)$ 76-105.[8]

[9]. Raju Nellutla, V. V Haragopal, (2015) " Performance of Management Schools in Secondary School Examinations of Andhra Pradesh State by Data Envelopment Analysis" International Journal of Scientific Research, Vol-4,issue9,pp.179-182.

[10]. Charnes, A, W. Cooper, \& $\quad$ E., Rhodes (1978) “Measuring the Efficiency of decision making units" European Journal of Operational Research vol. 2, pp. 429-444.

[11]. Banker, R.D., R.F. Charnes, \& W.W. Cooper (1984) “'Some Models for Estimating Technical and Scale Inefficiencies in Data Envelopment Analysis", Management Science vol. 30, pp. 1078-1092

Books:

[12]. Text book "Introduction to Data Envelopment Analysis and its Uses "by William W. Cooper, L M Seiford, Springer 